\title{
Residual Analysis of Insecticides (Lambda-cyhalothrin, Lufenuron, Thiamethoxam and Clothianidin) in Pomegranate Using GC- $\mu$ ECD or HPLC-UVD
}

\author{
Lina Hem, Jong-Hyouk Park and Jae-Han Shim* \\ Natural Products Chemistry Laboratory, Division of Applied Bioscience and Biotechnology, \\ College of Agriculture and Life Science, Chonnam National University, 300 \\ Yongbong-dong, Buk-gu, Gwangju 500-757, Republic of Korea \\ (Received September 15, 2010, Accepted September 25, 2010)
}

\begin{abstract}
In this study, the residual levels of four insecticidal compounds (lambda-cyhalothrin, lufenuron, thiamethoxam, and clothianidin) were monitored in the pomegranate, in order to assess the risk to consumers posed by the presence of such residues. The insecticides were applied at the recommended dose rates onto pomegranate trees. The samples were then collected at harvesting time after several treatments (two, three, and four treatments). After sample preparation progressed through the clean-up procedure, lufenuron, thiamethoxam, and clothianidin residues were analyzed via a HPCL-UVD, and the lambda-cyhalothrin residue was analyzed via a GC- $\mu$ ECD. The versatility of this method was evidenced by its excellent linearity $(>0.9998$ to 1) at broad concentration ranges. The mean recoveries evaluated from the untreated sample spiked with two different fortification levels ranged from 72.45 to $113.90 \%$, and the repeatability (as a relative standard deviation) resulted from triplicate recovery tests was in a range from 0.80 to $11.75 \%$. The residues of all insecticides determined from treated pomegranate samples and their LOD levels (lunfenuron, 0.01; lambda-cyhalothrin, 0.005; thiamethoxam, 0.01; clothianidin, $0.02 \mathrm{mg} / \mathrm{kg}$ ) were much lower than their MRLs (0.5 mg/kg).
\end{abstract}

Key Words: GC- $\mu$ ECD, HPLC-UVD, Insecticides, Pomegranate

\section{INTRODUCTION}

Pomegranate aril juice provides approximately $16 \%$ of an adult's daily vitamin $C$ requirement per $100 \mathrm{~mL}$ serving, and is also a good source of vitamin B5, potassium, and antioxidant polyphenols; the marked antioxidant activities of the pomegranate have been well established, and many clinical studies have demonstrated that pomegranate consumption contributes to the prevention of several diseases, such as coronary heart disease and certain types of cancer (Palou et al., 2007). Consumer demand for this fruit

\footnotetext{
*연락저자:

Tel: +82-62-530-2135 Fax: +82-62-530-0219

E-mail: jhshim@jnu.ac.kr
}

has recently been trending upward (Suhaibani and Ali, 2004). Pesticides have been employed broadly for pest control and weed control purposes, and also to promote crop growth; this has increased crop productivity in general.

Lambda-cyhalothrin, (R,S)-a-cyano-3-phenoxybenzyl (1S)-cis-3-[(Z)-2-chloro-3,3,3-trifluoropropenyl]-2,2-dim ethylcyclopropanecarboxylate, is a pyrethroid insecticide with a unique chemical configuration consisting principally of a dimethyl cyclopropane carboxylate moiety (Bonafos et al, 2007; Seenivasan and Muraleedharan, 2004; Çavaş et al., 2003). It exhibits marked activity against a broad range of chewing and sucking pests-in particular, Lepidoptera, Coleoptera, and mites infesting fruits, cereals, maize, cotton, wheat, pulses, and oilseeds; from a public health standpoint, lambda- 
cyhalothrin also functions effectively as a vector control agent.

Lufenuron, (RS)-1-[2,5-dichloro-4-(1,1,2,3,3,3-hexafluoropropoxy)phenyl]-3-(2,6-difluorobenzoyl) urea, is a benzoylphenylurean (BPU)-class insecticide, which functions as a chitin synthesis inhibitor (CSI). Doses of lufenuron higher than that recommended for anti-flea treatment have also proven quite effective in the treatment of dermatomycosis in dogs and cats (Ahrie et al., 2008; Khay et al., 2008). The compound appears to be minimally toxic to mammals, since its activity is highly specific to immature insects at the molting stage.

Thiamethoxam, 3-[(2-chloro-5-thiazoly)methyl] tetrahydro-5-methyl-N-nitro-4H-1,3,5-oxadiazin-4-imine, has been newly introduced to the American market in the past few years and has been approved for use as a soil, foliar, and seed treatment agent for the control of aphids, whiteflies, and certain beetles, among others(Campbell et al., 2005; Pandey et al., 2009; Rancan et al., 2006). It is applied during the growing season in different vegetable crops in India to control insects and fungal diseases (Singh et al., 2004).

Intensive pesticide use has resulted in contaminations of agricultural products, as well as soil and water. Pesticide residue analysis is essential to address rising consumer concerns regarding possible contamination issues. Cyhalothrin has been investigated in this regard primarily via HPLC methods, but a few studies using a HPLC-MS have also been performed recently (Seccia et al., 2008). Some authors' studies have dealt with the determination of thiamethoxam in various real samples using different methods; the LC-MS technique was employed by Obana et al. (Rancan et al., 2006; Pandey et al., 2009; Campbell et al., 2005; González et al., 2008). Five benzoylureas, including lufenuron in ground water samples and Chinese Cabbage, were previously evaluated using HPLC with different detectors - fluorescence (Garía et al., 2006) and ultraviolet detection as previously described by Gamon et al. (1998) (Khay et al., 2008). Lambda-cyhalothrin is mainly detected and analyzed via Gas Chromatography, but there have also been some research determinations of lambda-cyhalothrin in various samples using GC-ECD (Seenivasan and Muraleedharan, 2009; Bouldin et al., 2006).

The principal objective of this study was to develop and carry out a routinizable monitoring of the residue levels of lambda-cyhalothrin, lufenuron, thiamethoxam, and clothianidin in the pomegranate.

\section{MATERIALS AND METHODS}

\section{Chemicals}

Pesticides (lambda-cyhalothrin, lufenuron, thiamethoxam and clothianidin), all at above $98 \%$ purity, were provided by the Society of Pesticide Industries, Republic of Korea.

All reagents and solvents employed herein were of analytical-grade or HPLC-grade. Organic solvents were purchased from Baker NJ (USA), and sodium sulfate (anhydrous) and sodium chloride were supplied by Junsei Chemical Co., Ltd (Japan). The silica gel used for column chromatography cleanup was purchased from Sigma-Aldrich (USA). Solid phase extraction (SPE; florisil) cartridge was purchased from phenomenex (USA).

\section{Sample preparation}

Lambda-cyhalothrin, lufenuron, and thiamethoxam, including its metabolite clothianidin were extracted individually from pomegranate samples. Exactly $20 \mathrm{~g}$ of samples were homogenized with $100 \mathrm{~mL}$ of methanol-water $(50: 50, \mathrm{v} / \mathrm{v})$, methanol, or acetone, respectively, at $1200 \mathrm{rpm}$ for $5 \mathrm{~min}$ (WiselMix ${ }^{\mathrm{TM}} \mathrm{HG}-150$; Daehan Scientific, Korea). The homogenates were then filtered through Whatman filter paper (No. 6) (Whatman International Ltd, England) topped with Celite 545 (Daejun Chemicals and Materials Co., Ltd. Korea) in a porcelain Büchner funnel, and subsequently washed with the same extraction solvent. The filtrates for lambda-cyhalothrin and lufenuron were partitioned with $100 \mathrm{~mL}$ dichloromethane and n-hexane, respectively; whereas the filtrates for thiamethoxam and its metabolite clothianidin were filled up to a volume of $200 \mathrm{~mL}$ and a $50 \mathrm{~mL}$ sample was subjected to portioning with $100 \mathrm{~mL}$ of $n$-hexane. Partitioning was enhanced by salting-out with $50 \mathrm{~mL}$ saturated $\mathrm{NaCl}$. The partitioned organic layers were then dehydrated through sodium sulfate (anhydrous) and evaporated to dryness in a rotary vacuum evaporator (Büchi Rotavapor R0114, Switzerland) at $40^{\circ} \mathrm{C}$. The residues for lambda-cyhalothrin and lufenuron were dissolved in $4 \mathrm{~mL} n$-hexane and that for thiamethoxam and 
clothianidin in $5 \mathrm{~mL}$ dichloromethane for cleanup.

Clean-up for lambda-cyhalothrin and lufenuron was conducted using open preparative chromatographic columns packed with $5 \mathrm{~g}$ silica gel and $2 \mathrm{~g}$ sodium sulfate anhydrous $\left(\mathrm{Na}_{2} \mathrm{SO}_{4}\right)$ placed atop the columns. The columns were then activated with $30 \mathrm{~mL}$ $n$-hexane followed by sample extract loading, after which the analytes were eluted with the appropriate solvents. Lambda-cyhalothrin was eluted with $50 \mathrm{~mL}$ acetone-n-hexane $(10: 90, \mathrm{v} / \mathrm{v})$, while lufenuron was eluted with $50 \mathrm{~mL}$ acetone-n-hexane (15:85, v/v) after continuous washing with $50 \mathrm{~mL} n$-hexane-acetone (95:5, v/v) and $50 \mathrm{~mL} n$-hexane-acetone (90:10, v/v). The eluates were evaporated in vacuo at $40^{\circ} \mathrm{C}$ and then lambda-cyhalothrin was re-dissolved in $2 \mathrm{~mL}$ $n$-hexane and lufenuron in n-hexane-propanol-methanol (90:5:5, v/v), lambda-cyhalothrin and lufenuron were analyzed via GC- $\mu E C D$ and HPLC-UVD, respectively.

Thiamethoxam and clothianidin were purified using SPE cartridges (florisil $1000 \mathrm{~g} / 6 \mathrm{~mL}$ ), conditioned with $5 \mathrm{~mL}$ dichloromethane. Sample extracts were loaded onto the cartridges. The samples were washed with $10 \mathrm{~mL}$ dichloromethane-acetone $(96: 4, \mathrm{v} / \mathrm{v})$ and eluted with $25 \mathrm{~mL}$ dichloromethane-acetone (55:45, $\mathrm{v} / \mathrm{v})$. The eluates were evaporated in vacuo at $30^{\circ} \mathrm{C}$ and re-dissolved in $2 \mathrm{~mL}$ methanol-water (50:50, $\mathrm{v} / \mathrm{v})$, and then analyzed via HPLC/UVD.

\section{Method validation}

Stock solutions at $100 \mu \mathrm{g} / \mathrm{mL}$ of lambda-cyhalothrin, lufenuron, thiamethoxam, and clothianidin were prepared in acetone, respectively. Working solutions of the analytes were prepared with an adequate solvent at different six concentrations as follows; 0.025, 0.05, $0.1,0.25,0.5$, and $1 \mu \mathrm{g} / \mathrm{mL}$ in $\mathrm{n}$-hexane for thiamethoxam; $0.1,0.5,1,2,4$, and $5 \mu \mathrm{g} / \mathrm{mL}$ in $n$-hexane-propanolmethanol $(90: 5: 5, \mathrm{v} / \mathrm{v} / \mathrm{v})$ for lufenuron; 0.025, 0.05, $0.1,0.5,1$, and $2 \mu \mathrm{g} / \mathrm{mL}$ for thiamethoxam and 0.05 , $0.1,0.2,1,2$, and $4 \mu \mathrm{g} / \mathrm{mL}$ for clothianidin in methanol-water (50:50, v/v), respectively. All stock and working solutions were stored at $-24^{\circ} \mathrm{C}$ during study. Calibration curves were created by the peak area versus the concentration of the analytes' working solutions.

To validate the analytical method, recovery tests were examined by spiking working solutions into blank samples at different two concentrations in trip- licate. The spiked levels were 0.05 and $0.2 \mathrm{mg} / \mathrm{kg}$ for lambda-cyhalothrin, 0.2 and $0.4 \mathrm{mg} / \mathrm{kg}$ for lufenuron, 0.1 and $0.5 \mathrm{mg} / \mathrm{kg}$ for thiamethoxam, and 0.2 and 1 $\mathrm{mg} / \mathrm{kg}$ for clothianidin.

Limits of detection (LODs) of the analytes were assessed with a signal-to-noise ratio ( $\mathrm{S} / \mathrm{N}$ ratio). Appropriate concentrations prepared in blank extracts were detected by their own analytical instruments, individually, and every peak height of the analytes was compared with the blank signals.

\section{CONDITIONS OF ANALYTICAL INSTRUMENTS}

\section{GC- $\mu \mathrm{ECD}$}

Lambda-cyhalothrin analysis was conducted using an Agilent Technologies 7890 A GC System (USA) consisting of a model 7683B autoinjector and an $\mu$-electron capture detector. Chromatographic separation was conducted using an HP-5 (50 m $\times 0.25 \mathrm{~mm}, 0.25$ $\mu \mathrm{m}$ film thickness) column. The oven temperature was held at $120^{\circ} \mathrm{C}$ for $5 \mathrm{~min}$ and then increased to $2700^{\circ} \mathrm{C}$ at a rate of $5^{\circ} \mathrm{C} / \mathrm{min}$ for $5 \mathrm{~min}$. The injection port and detector temperatures were maintained at $250^{\circ} \mathrm{C}$ and $280^{\circ} \mathrm{C}$, respectively. The injection volume was $2 \mu \mathrm{L}$, and the column was flowed with nitrogen gas at 1 $\mathrm{mL} / \mathrm{min}$.

\section{HPLC-UVD}

Lufenuron analysis was conducted using a Kontron HPLC system (Italy) consisting of a 355 UV-detector and a 322 pump. Chromatographic separation was conducted using a Waters Spherisorb® $5 \mu \mathrm{L} \mathrm{NH}_{2}, 4.6$ $\times 250 \mathrm{~mm}$. The mobile phase was a mixture of n-hexane-propanol-methanol (90:5:5, v/v) and $20 \mu \mathrm{L}$ of sample was injected into an HPLC column. Lufenuron was detected at a wavelength of $250 \mathrm{~nm}$, and the detected time of lufenuron was $12.92 \mathrm{~min}$.

Analysis of thiamethoxam and clothianidin was conducted using the Shimadzu liquid chromatography system equipped with a SCL-10AVP system controller, LC-6AD pumps, and a SPD-10AVP UV-vis detector (Shimadzu, Kyoto, Japan). An Aqua C18 $200 \AA$ (4.6×250 $\mathrm{mm}, 5.0 \mu \mathrm{m}$, Phenomenex, USA) was employed as an analytical column for the target compound. The mobile phase was a mixture of methanol-water $(30: 70, \mathrm{v} / \mathrm{v})$, and the flow rate was $0.6 \mathrm{~mL} / \mathrm{min}$. $20 \mu \mathrm{L}$ of sample was injected onto the HPLC column. Thiamethoxam 
and clothianidin were detected at a wavelength of $230 \mathrm{~nm}$; the detection time of thiamethoxam was $10.60 \mathrm{~min}$, and $16.57 \mathrm{~min}$ for clothianidin.

\section{RESULTS AND DISCUSSION}

\section{Extraction}

In this study, pesticides were extracted from pomegranate fruits via liquid-liquid extraction. The whole procedures were simply divided into the following steps: extraction with a polar solvent, liquidliquid partition with a polar solvent, and cleanup with an open preparative chromatographic column packed with a polar sorbent or an SPE cartridge. A few methods have been previously developed for the determination of lufenuron residues in various matrices, including fruit, vegetables, blood, and groundwater. These studies have generally employed liquid chromatography with mass spectrometric, fluorescence, or diodearray detection, and the procedures have generally been derived from solvent partitioning and solid phase extraction protocols (Brito et al., 2002; Khay et al., 2008). The n-hexane partition cleanup procedure appears to effectively remove interfering co-extractives for HPLC analysis (Singh et al., 2004). The n-hexane partition procedure for the analysis of the insecticide lambda-cyhalothrin was previously developed and described by Seenivasan et al. (2009) (Seenivasan and Muraleedharan, 2009), in a study of the residues of lambda-cyhalothrin in tea, and Singh et al. (2004) (Singh et al., 2004) used a similar method to analyze thiamethoxam residues in fresh and cooked vegetable samples. The sample preparation method employed in this study also resulted in reliable results, which were demonstrated in the validation results.

\section{Linearity}

Lambda-cyhalothrin, lufenuron, thiamethoxam and clothianidin evidenced good linearity at the different concentrations employed. The linear equations were as follows: $\mathrm{Y}=21565.02 \mathrm{x}+650.47 ; \mathrm{Y}=61.009 \mathrm{x}+3.6892$; $Y=104382.92 x-628.87$; and $Y=62164.83 x-374.25$, respectively. The correlation coefficients $\left(r^{2}\right)$ ranged from 0.9998 to 1 .

\section{Recovery}

The analytical methods were validated for the black pomegranate prior to actual analysis. In an effort to validate the analytical method, the recovery percentage was established via the fortification of standard solutions of lambda-cyhalothrin, lufenuron, thiamethoxam, and clothianidin. The achieved recoveries ranged from $73.61 \%$ to $108.89 \%$ with a standard deviation of $\pm 11.45 \%$, which indicated that the mean recovery should be within a range of $70-110 \%$ in order to sufficiently validate the quantitative methods. These results were also fitted in accordance with the relevant international guidelines (SANCO, 2004).

\section{Limit of detection (LOD)}

The LODs were calculated considering a value 3 times the background noise obtained for blank samples, which also included the instrument noise. The calculated LODs were 0.005 (lambda-cyhalothrin), 0.01 (lufenuron), 0.01 (thiamethoxam), and $0.02 \mathrm{mg} / \mathrm{kg}$ (clothianidin) (Table 1). All limits were substantially lower than the MRLs of $0.5 \mathrm{mg} / \mathrm{kg}$ established by the Korea Food and Drug Administration (KFDA, 2005).

\section{Stability of the analytes}

The residue analyses of the field samples were conducted subsequent to the completion of the experimental procedures. As the determination of lambdacyhalothrin, lufenuron, thiamethoxam, and clothianidin residues could be delayed as the result of unforeseen systematic errors and/or poor preliminary experimental results, the actual residues could be altered by chemical or metabolic reactions with sample matrices during storage. Therefore, it is necessary that the stability of the analytes be evaluated in samples stored

Table 1. Calibration curve and linearity of the analytes

\begin{tabular}{cclc}
\hline Pesticides & Concentration range $(\mathrm{mg} / \mathrm{kg})$ & Equation & $r^{2}$ value \\
\hline Lambda-cyhalothrin & $0.025-6$ & $\mathrm{Y}=21565.02 \mathrm{x}+650.47$ & 1 \\
Lufenuron & $0.1-5$ & $\mathrm{Y}=61.009 \mathrm{x}+3.6892$ & 0.9998 \\
Thiamethoxam & $0.025-2$ & $\mathrm{Y}=104382.92 \mathrm{x}-628.87$ & 1 \\
Clothianidin & $0.05-4$ & $\mathrm{Y}=62164.83 \mathrm{x}-374.25$ & 1 \\
\hline
\end{tabular}


Table 2. Validation of the analytical method of compounds in pomegranate

\begin{tabular}{|c|c|c|c|c|c|c|c|}
\hline \multirow{2}{*}{ Insecticides } & \multirow{2}{*}{$\begin{array}{l}\text { Concentration } \\
(\mathrm{mg} / \mathrm{kg})\end{array}$} & \multicolumn{3}{|c|}{ Recovery (\%) } & \multirow{2}{*}{$\begin{array}{c}\text { Average } \\
(\%)\end{array}$} & \multirow{2}{*}{$\begin{array}{l}\text { SD } \\
(\%)\end{array}$} & \multirow{2}{*}{$\begin{array}{c}\text { LOD } \\
(\mathrm{mg} / \mathrm{kg})\end{array}$} \\
\hline & & I & II & III & & & \\
\hline \multirow{2}{*}{ Lambda-cyhalotherin } & 0.05 & 85.41 & 91.04 & 90.00 & 82.70 & 5.75 & \multirow[t]{2}{*}{0.005} \\
\hline & 0.2 & 95.46 & 81.59 & 85.97 & 87.67 & 7.09 & \\
\hline \multirow{2}{*}{ Lufenuron } & 0.2 & 95.75 & 101.59 & 88.52 & 95.15 & 6.35 & \multirow{2}{*}{0.01} \\
\hline & 0.4 & 113.9 & 105.14 & 91.19 & 103.41 & 11.45 & \\
\hline \multirow{2}{*}{ Thiamethoxam } & 0.1 & 86.64 & 90.49 & 84.34 & 87.15 & 3.11 & \multirow{2}{*}{0.01} \\
\hline & 0.5 & 72.45 & 74.50 & 73.89 & 73.61 & 1.05 & \\
\hline \multirow{2}{*}{ Clothianidin } & 0.2 & 87.37 & 90.89 & 110.40 & 108.89 & 3.53 & \multirow{2}{*}{0.02} \\
\hline & 1 & 87.37 & 90.89 & 88.72 & 88.99 & 1.77 & \\
\hline
\end{tabular}

Table 3. Storage stability of the analytes

\begin{tabular}{cccccc}
\hline \multirow{2}{*}{ Pesticides } & Spiked & \multicolumn{3}{c}{ Recovery (\%) } & \multirow{2}{*}{ Average (\%) } \\
\cline { 3 - 5 } & concentration & I & II & III & $91.03 \pm 9.27$ \\
Lambda-cyhalothrin & 5 & 93.97 & 98.42 & 80.62 & $99.18 \pm 11.75$ \\
Lufenuron & 0.4 & 105.05 & 85.61 & 106.27 & $70.48 \pm 0.89$ \\
Thiamethoxam & 0.5 & 71.06 & 69.45 & 70.93 & $86.40 \pm 3.30$ \\
Clothianidin & 1 & 85.04 & 90.16 & 84.00 & \\
\hline
\end{tabular}

Table 4. Residue levels of the analytes in field-incurred pomegranates

\begin{tabular}{cccc}
\hline Spraying times & $\begin{array}{c}\text { Lambda-cyhalothrin } \\
(\mathrm{mg} / \mathrm{kg})\end{array}$ & $\begin{array}{c}\text { Lufenuron } \\
(\mathrm{mg} / \mathrm{kg})\end{array}$ & $\begin{array}{c}\text { Thiamethoxama } \\
(\mathrm{mg} / \mathrm{kg})\end{array}$ \\
\hline Control & $<0.01$ & $<0.01$ & $<0.01$ \\
2 & 0.011 & 0.063 & 0.100 \\
2 & 0.004 & 0.049 & 0.110 \\
3 & 0.011 & 0.118 & 0.130 \\
3 & 0.014 & 0.08 & 0.100 \\
4 & 0.016 & 0.12 & 0.160 \\
4 & 0.010 & 0.097 & 0.080 \\
\hline
\end{tabular}

${ }^{\mathrm{a}}$ Thiamethoxam residues were calculated in conjunction with clothianidin residues.

for experimental periods of time. Blank samples were fortified with lambda-cyhalothrin, lufenuron, thiamethoxam, and clothianidin at levels of 5, 0.4, 0.5, and $1 \mathrm{mg} / \mathrm{kg}$ for each matrix in triplicate in order to test storage stability of the analytes. The storage stability was evaluated by recovery test, and their rates were $91.03 \pm 9.27,99.18$ $\pm 11.75,70.48 \pm 0.89$ and $86.40 \pm 3.30 \%$, respectively. This indicates that all of these compounds are relatively stable in samples under storage conditions during the experimental time period of this study.

\section{Analysis of field-incurred samples}

The analytical method was applied to analyses of the treated samples. Very small quantities of lambdacyhalothrin, lufenuron, thiamethoxam, and clothianidin were detected in pomegranates treated for different application times. Although the insecticides were detected in the pomegranate, the detected levels were lower than the MRLs for each compound established by the Korea Food and Drug Administration (2005). The residues obtained can be attributed principally to growth dilution occurring between application and sampling, as well as to the volatilization associated with application, removal by weathering, heat decomposition, sunlight UV radiation, or other complex conditions. 

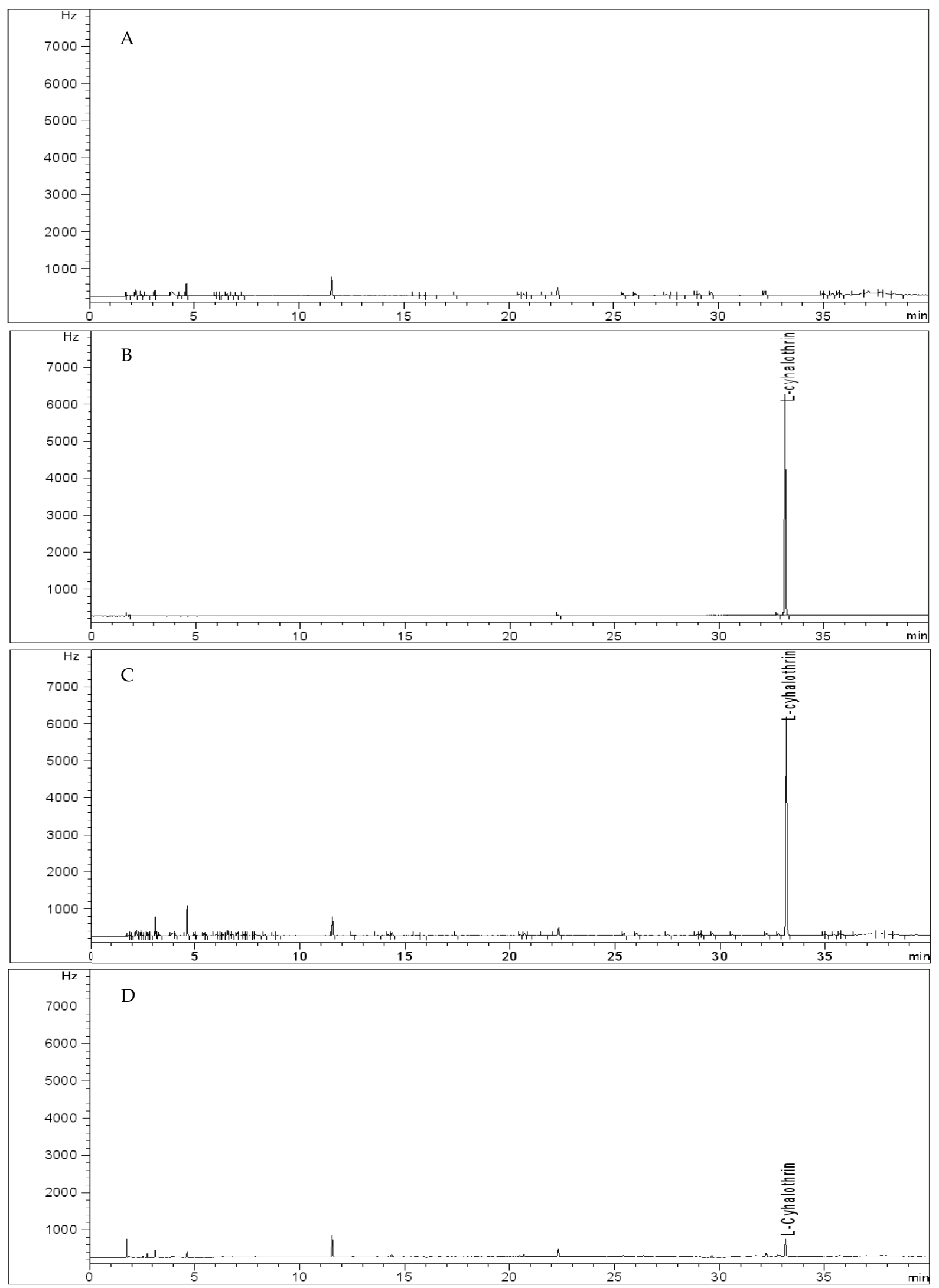

Fig. 1. Typical GC- $\mu E C D$ chromatograms of lambda-cyhalothrin; control pomegranate (A), standard at $1 \mu \mathrm{mL}$ (B), recovery sample at $0.2 \mathrm{mg} / \mathrm{kg}(\mathrm{C})$, and treated sample 4 times (D). 

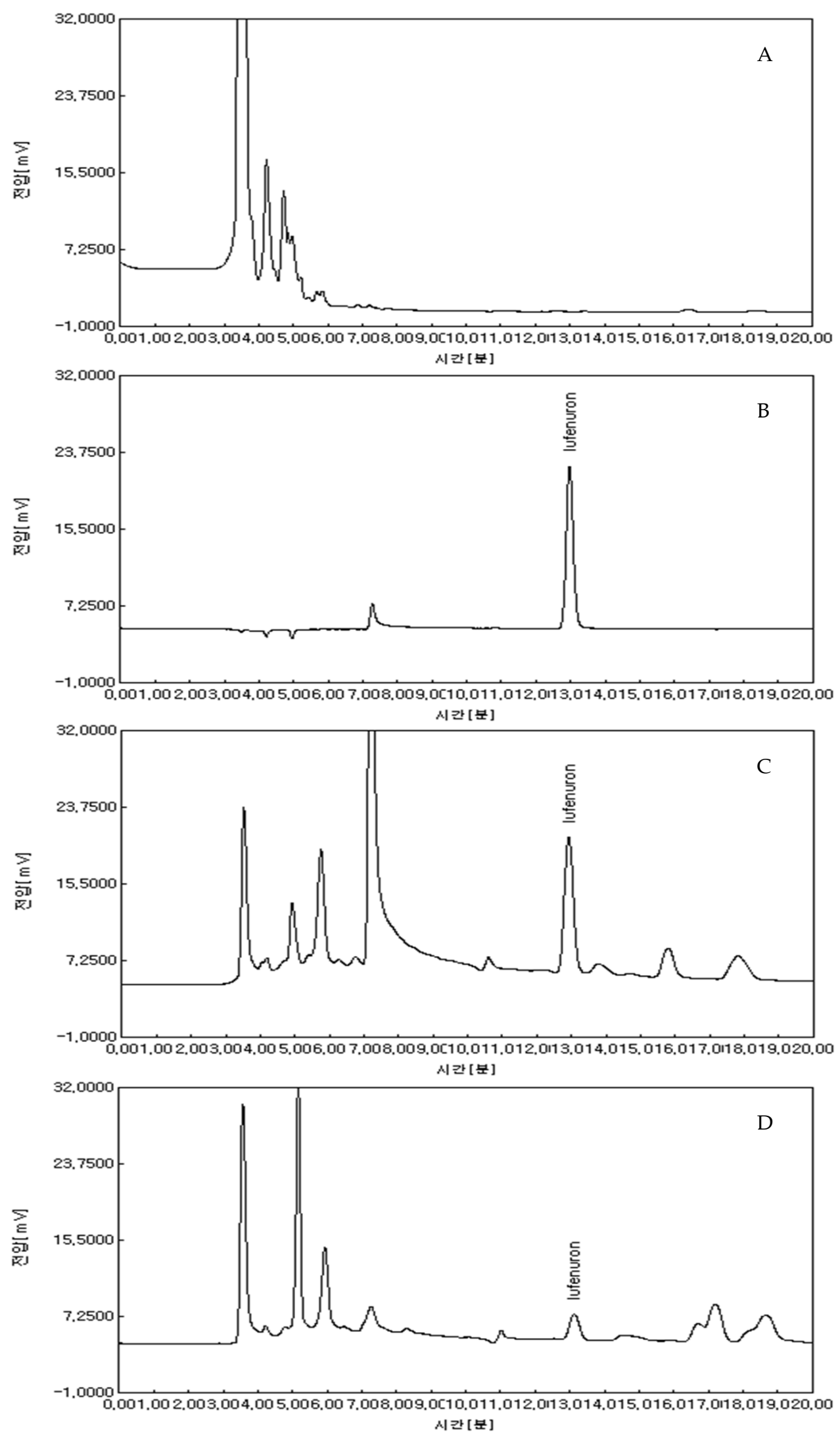

Fig. 2. Typical HPLC chromatograms of lufenuron; control pomegranate (A), standard at $4 \mu \mathrm{g} / \mathrm{mL}$ (B), recovery sample at $0.4 \mathrm{mg} / \mathrm{kg}(\mathrm{C})$, and treated sample 2 times (D). 

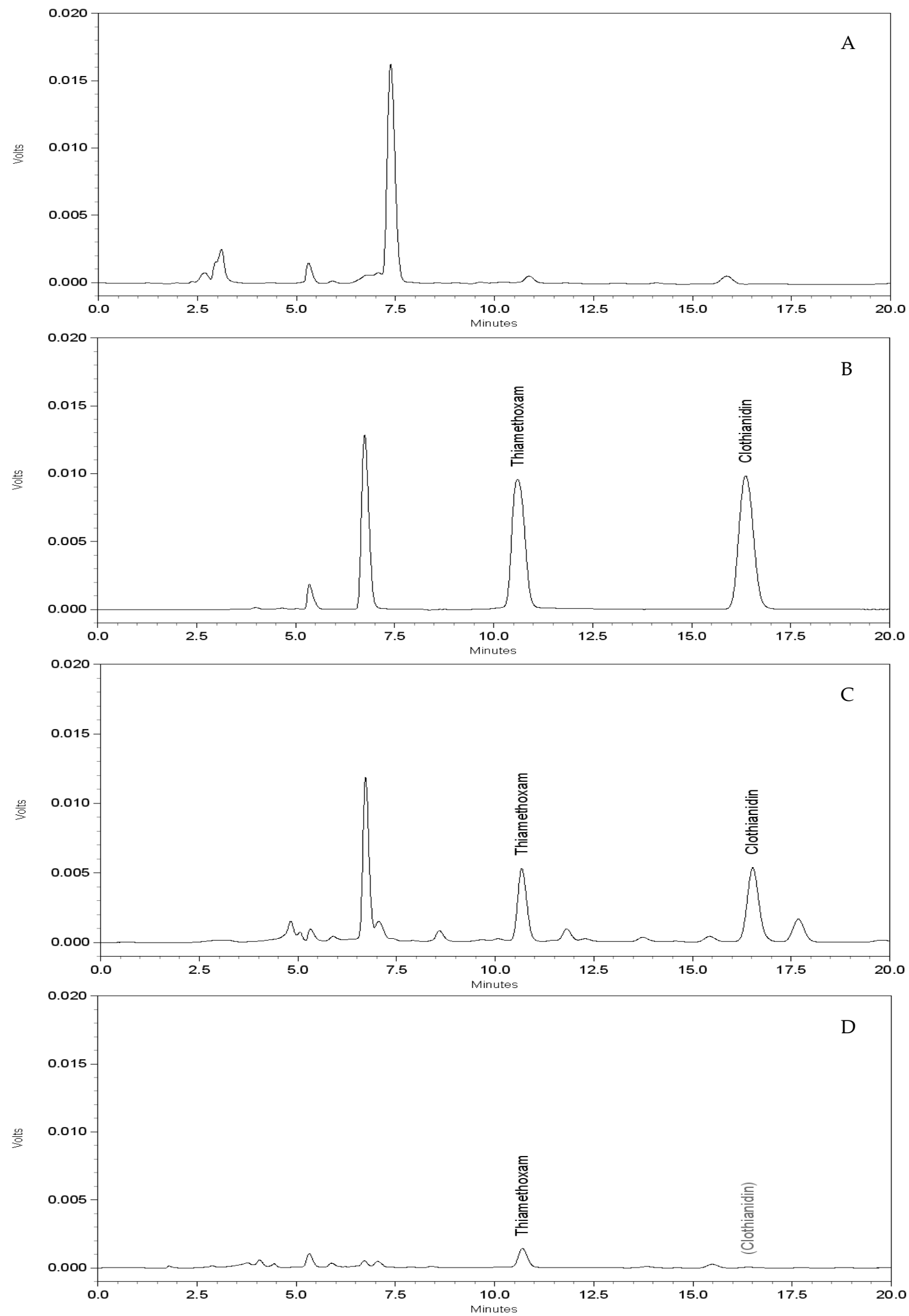

Fig. 3. Typical HPLC chromatograms of thiamethoxam and clothianidin; control pomegranate (A), standard thiamethoxam at $1 \mu \mathrm{g} / \mathrm{mL}$ and clothianidin at $2 \mu \mathrm{g} / \mathrm{mL}$ (B), recovery sample thiamethoxam at $0.5 \mathrm{mg} / \mathrm{kg}$ and clothianidin at $1 \mathrm{mg} / \mathrm{kg}(\mathrm{C})$, and treated sample 2 times (D). 


\section{ACKNOWLEDGEMENT}

This work was supported by the National Agricultural Products Quality Management Services (NAQS), Gwangju, Republic of Korea.

\section{REFERENCES}

Ahrie, K.C., Arora, M.S., Mukherjee, S.N., 2008. Development and application of a method for analysis of lufenuron in wheat flour by gas chromatography-mass spectrometry and confirmation of bio-efficacy against Tribolium castaneum (Herbst) (Coleoptera: Tenebrionidae), J. Chromatogr. B 861, 16-21.

Al-suhaibani, A.M., Ali, A.G., 2004. Susceptibility of some pomegranate fruit cultivars to myelois ceratonia zeller (Lepidoptera:phycitidae) with some notes on its population fluctuation and control measures, Minia J. of Agric. Res. E Develop. 24, 335-346.

Bonafos, R., Serrano, E., Auger, P., Kreiter, S., 2007. Resistance to deltamethrin, lambda-cyholathrin and chlorpyriphos-ethyl in some populations of Typhlodromus pyri Scheuten and Amblyseius andersoni (Chant) (Acari:Phytoseiidae) from vineyards in the south-west of France, J. Crop Pro. 26, 169-172.

Bouldin, J.L., Farris, J.L., Moore, M.T., Smith, Jr.S., Cooper, C. M., 2006. Hydroponic uptake of atrazine and lambda-cyhalothrin in Juncus effusus and Ludwigia peploides, Chemosphere 65, 1049-1057.

Brito, N.M., Navickiene, S., Polese, L., Jardim, E.F.G., Abakerli, R.B., Ribeiro, M.L., 2002. Determination of pesticide residues in coconut water by liquidliquid extraction and gas chromatography with electron-capture plus thermionic specific detection and solid-phase extraction and high-performance liquid chromatography with ultraviolet detection, J. Chromatogr. A, 957, 201-209.

Campbell, S., Chen, L., Yu, J., Li, Q.X., 2005. Adsorption and analysis of the insecticide Thiamethoxam and Indoxacarb in Hawaiian Soil, J. Agric. Food Chem. 53, 5373-5376.

Çavaş, T., Gözükara, S.E., 2003. Evaluation of the genotoxic potential of lambda-cyhalothrin using nuclear and nucleolar biomarkers on fish cells, Mutat. Res. Genet. Toxicol. Environ. Mutagen. 534, 93-99.

Garía, M.D.G., Galera, M.M., Martínez, D.B., Gallego,
J.G., 2006. Determination of benzoylureas in ground water samples by fully automated on-line pre-concentration and liquid chromatography-fluorescence detection, J. Chromatogr. A, 1103, 271-277.

González, R.R., Frenich, A.G., Vidal, J.L.M., 2008. Multiresidue method for fast determination of pesticides in fruit juice by ultra performance liquid chromatography coupled to tandem mass spectrometry, Talanta 76, 211-225.

Khay, S., Choi, J.-H., Abd El-Aty, A.M., Mamun, M.I.R., Park, B.-J., Goudah, A., Shin, H.C, Shim, J.H., 2008. Dissipation Baehavior of Lufenuron, Benzoylphenylurea Isecticide, in/on Chinses Cabbage Applied by Foliar Spraying Under Greenhouse Condition, Bull. Environ. Contam. Toxicol. 81, 369-372.

Palou, L., Crisosto, C.H., Garner, D., 2007. Combination of postharvest antifungal chemical treatments and controlled atmosphere storage to control gray mold and improve storability of 'Wonderful' pomegranates, Postharvest Biol. Technol. 43, 133-142.

Rancan, M., Rossi, S., Sabatini, A.G., 2006. Determination of Thiamethoxam residues in honeybees by high performance liquid chromatography with an electrochemical detector and post-column photochemical reactor, J. Chromatogr. A, 1123, 60-65.

Pandey, G., Dorrian, S.J., Russell, R.J., Oakeshott, J.G., 2009. Biotransformation of the neonicotinoid insecticides imidacloprid and thiamethoxam by Pseudomonas sp. 1G, J. Biochem. Biophys. Res. Commun. 380, 710-714.

SANCO, Quality control procedures for pesticides residue analysis. European Commission, Directorate General Health and Consumer Protection. Document no. SANCO/10476/2003, February 2004.

Seenivasan, S., Muraleedharan, N.N., 2009. Residues of lambda-cyhalothrin in tea, Food Chem. Toxicol. 47, 502-505.

Seccia, S., Fidente, P., Montesano, D., Morrica, P., 2008. Determination of neonicotinoid insecticides in bovine milk samples by solid-phase extraction clean-up and liquid chromatography with diodearray detection, J. Chromatogr. A, 1214, 115-120.

Singh, S.B., Foster, G.D., Khan, S.U., 2004. Microwave-assisted extraction for the simultaneous determination of thiamethoxam, imidacloprid, and carbndazim residues in fresh and cooked vegetable sample, J. Agric. Food Chem. 52, 105-109. 